\title{
Correlation Between Malnutrition and Dental Caries in Children
}

\author{
Shakya $A^{1}$, Shenoy $R^{2}$, Rao $A^{3}$ \\ ${ }^{1}$ Dr. Ajay Shakya, MDS, Assistant Prof., Department \\ of Community Dentistry, Chitwan Medical College \\ Teaching Hospital, Chitwan, Nepal, ${ }^{2} \mathrm{Dr}$. Ramya \\ Shenoy, MDS, Assoc. Professor, Department of Public \\ Health Dentistry, Manipal College of Dental Sciences, \\ Mangalore, India, ${ }^{3} \mathrm{Dr}$. Ashwini Rao, MDS, Professor \\ and Head of Department, Department of Public \\ Health Dentistry, Manipal College of Dental Sciences, \\ Mangalore, India.
}

\section{Introduction}

$\mathrm{D}$ ental caries is a multifactorial infectious disease. Factors affecting the onset of dental caries include oral hygiene, diet composition and frequency, socioeconomic status, salivary immunoglobulins, bacterial load, and fluoride intake ${ }^{1}$. It is identified as the single most common chronic childhood disease ${ }^{2}$. Although dental caries prevalence and severity in children has dramatically decreased over the last three decades, significant levels of disease persist and are concentrated among socioeconomically disadvantaged groups $^{3}$, especially in the developing countries ${ }^{4,5}$.

Malnutrition is a serious global issue ${ }^{6}$ and is considered a health problem in developing countries ${ }^{7}$. The World Bank estimates that India is ranked $2^{\text {nd }}$ in the world of the number of children suffering from malnutrition, and the prevalence of underweight children in India is among the highest in the world ${ }^{2}$. A report by WHO states that socioeconomic inequality in childhood malnutrition existed throughout the developing world ${ }^{8}$.

Although it has been well documented in animals that early malnutrition affects tooth development and eruption and results in increased dental caries later in life, it has not been directly demonstrated in humans ${ }^{1}$. A strong correlation was observed between the degree of linear enamel hypoplasia and caries experience in the deciduous teeth of undernourished Guatemalan children $^{9}$. Notably, malnutrition (wasting or stunting)

\begin{abstract}
Introduction: Dental caries and malnutrition is a public health problem, concentrated more among socioeconomically disadvantaged groups. This study aimed to evaluate the correlation between malnutrition and dental caries among 6, 10 and 12 years children in Mangalore. Materials and Methods: Data about oral health status and body mass index of children of age groups 6,10 and 12 were collected using a cross-sectional design. Anthropometric measurements and oral examinations were carried out. Statistical test was performed to look for categorical associations between BMI categories and dental caries prevalence and to see if any correlation exists between BMI Score and dental caries severity. Results: The Pearson correlation test result suggested children with less BMI score tend to have more caries affected teeth than children with normal BMI. Conclusions: Physicians and dentists treating young children should consider malnutrition as a risk marker for childhood caries. Inclusion of BMI calculation in the standard dental evaluation of any pediatric patient can provide a screen for prevention, timely diagnosis, and treatment of the children suffering from dental caries and malnutrition.
\end{abstract}

Key words: Dental caries, Malnutrition, Body mass index, Socio-economic status

is associated with enhanced susceptibility to caries because of impaired saliva secretion and composition ${ }^{10}$.

The prevalence of dental caries is high in children from lower socioeconomic groups and are often poorly nourished and suffer delayed growth and development compared with their healthy peers ${ }^{11}$. In these populations, prenatal and perinatal malnutrition are often the causes of enamel hypoplasia, reduced salivary secretion and low buffering capacity ${ }^{12}$.

\section{Address for correspondence \\ Dr. Ajay Shakya \\ Department of Community Dentistry \\ Chitwan Medical College Teaching Hospital \\ Bharatpur-10, Nepal \\ E-mail:drajayshakya@gmail.com}

This work is licensed under a Creative Commons Attribution 3.0 License.

\section{How to cite this article?}

Shakya A, Shenoy R, Rao A. Correlation Between Malnutrition and Dental Caries in Children. J Nepal Paediatr Soc 2013;33(2):99-102. 
As lower socioeconomic status is a risk factor common to both dental caries and childhood malnourishment, and very few studies have been conducted till date, which probe into the association, a study was conducted to find out the correlation between malnutrition and dental caries among 6, 10 and 12 years low socioeconomic status children in Mangalore.

\section{Materials and Methods}

A cross-sectional study was carried out among children attending free dental examination in Mangalore city, India. The study was limited to children who were 6 , 10 and 12 years old, and whose parents gave consent to participate in the study. The age groups were chosen so that the results of the study could be correlated in terms of primary tooth caries, mixed dentition caries and permanent tooth caries.

Anthropometric measures were carried out by trained nurses. Height (recorded to the nearest centimeter) and body weight (to the nearest $0.1 \mathrm{~kg}$ ) was measured on validated scales when the child wore light clothing but no shoes. Body mass index (BMI: weight/ height in $\mathrm{kg} / \mathrm{m} 2$ ) was calculated and compared with the gender- and age-adjusted cut-off points. Children were classified into 4 categories using age- and genderspecific criteria: underweight - less than $5^{\text {th }}$ percentile; normal weight $-5^{\text {th }}$ percentile to less than $85^{\text {th }}$ percentile; at risk of overweight $-85^{\text {th }}$ to less than $95^{\text {th }}$ percentile; and overweight - equal to or greater than $95^{\text {th }}$ percentile.

Oral health examinations were conducted with a mouth mirror and a No. 23 explorer under good operating light. The World Health Organization basic methods for oral health surveys were used for dental caries scoring ${ }^{13}$. Only the decayed and filled teeth were recorded (dft/DFT: sum of decayed and filled teeth). Because of difficulty of correctly distinguishing among teeth extracted for caries and other reasons, such as exfoliation and trauma, missing teeth count was not included in the analysis.

Statistical test was performed with SPSS version 11.5. Chi-square $(X 2)$ test was done to predict categorical associations between BMI categories and dental caries prevalence. Correlation test was performed to see for relation between BMI Score and dental caries severity.

\section{Results}

A total of 248 children participated in the study, among them $28.6 \%$ were of 6 years, $33.1 \%$ were of 10 years and $38.3 \%$ were of 12 years of age. In total, $42.3 \%$ of the children were underweight, and $57.7 \%$ of them were found to be normal weight. (Table 1) Among children of 6,10 and 12 years of age, the percentage of underweight children were $42.3 \%, 46.3 \%$ and $38.9 \%$ respectively. (Table 2) The percentage of underweight children was found to be higher in males than in females (48.9\% versus $38.6 \%$ ); however the difference was not found to be significant.

Approximately $70.2 \%$ of the children had dental caries in 1 or more teeth (Table 3 ), and was highest in 6 years age group (83.1\%) followed by $10(67.1 \%)$ and 12 years of age $(63.2 \%)$. The differences were found to be significant. (Table 4)

Mean DFT at 6 years was $3.17 \pm 2.94$, at 10 years, it was $2 \pm 2.61$. Mean DFT for permanent dentition was $0.66 \pm 1.16$ at 10 years and $1.16 \pm 1.66$ at 12 years of age. (Table 5)

The overall dental caries prevalence was found to be almost equal in normal weight children and underweight children $(71.3 \%$ and $68.6 \%$ respectively). (Table 6)

A Pearson correlation test was performed between Body Mass Index score and dft score of deciduous dentition. A negative correlation (-0.016) was obtained. Similarly the Pearson correlation test was performed for DFT score of permanent dentition of age groups 10 and 12. A negative correlation was observed in both age groups ( -0.108 and -0.033 respectively). The result suggested children with less BMI score tend to have more approximal caries affected teeth than children with normal BMI. But the association was weak.

Table 1: Distribution of study population-BMI category wise

\begin{tabular}{|c|c|c|}
\hline BMI category & Frequency & Percent \\
\hline Underweight & 105 & 42.3 \\
\hline Normal & 143 & 57.7 \\
\hline Total & $\mathbf{2 4 8}$ & $\mathbf{1 0 0}$ \\
\hline
\end{tabular}

Table 2: Distribution of BMI Category-Age wise

\begin{tabular}{|c|c|c|c|}
\hline \multirow{2}{*}{ Age } & \multicolumn{2}{|c|}{ BMI category } & \multirow{2}{*}{ Total } \\
\cline { 2 - 3 } & Underweight & Normal & \\
\hline 6 years & 30 & 41 & 71 \\
\hline & $42.3 \%$ & $57.7 \%$ & $100 \%$ \\
\hline 10 years & 38 & 44 & 82 \\
\hline & $46.3 \%$ & $53.7 \%$ & $100 \%$ \\
\hline 12 years & 37 & 58 & 95 \\
\hline & $38.9 \%$ & $61.1 \%$ & $100 \%$ \\
\hline Total & $\mathbf{1 0 5}$ & $\mathbf{1 4 3}$ & $\mathbf{2 4 8}$ \\
\hline & $\mathbf{4 2 . 3} \%$ & $\mathbf{5 7 . 7} \%$ & $\mathbf{1 0 0} \%$ \\
\hline
\end{tabular}


Table 3: Dental caries prevalence

\begin{tabular}{|l|c|c|}
\hline Dental caries prevalence & Frequency & Percent \\
\hline No decay present & 74 & 29.8 \\
\hline Decay present & 174 & 70.2 \\
\hline Total & $\mathbf{2 4 8}$ & 100 \\
\hline
\end{tabular}

Table 4: Dental caries prevalence - Age wise

\begin{tabular}{|c|c|c|c|}
\hline \multirow{2}{*}{ Age } & \multicolumn{2}{|c|}{ Dental caries prevalence } & \multirow{2}{*}{ Total } \\
\cline { 2 - 4 } & No decay present & $\begin{array}{c}\text { Decay } \\
\text { present }\end{array}$ & \\
\hline 6 & 12 & 59 & 71 \\
\hline & $16.9 \%$ & $83.1 \%$ & $100 \%$ \\
\hline 10 & 27 & 55 & 82 \\
\hline & $32.9 \%$ & $67.1 \%$ & $100 \%$ \\
\hline 12 & 35 & 60 & 95 \\
\hline & $36.8 \%$ & $63.2 \%$ & $100 \%$ \\
\hline Total & $\mathbf{7 4}$ & $\mathbf{1 7 4}$ & $\mathbf{2 4 8}$ \\
\hline & $\mathbf{2 9 . 8 \%}$ & $\mathbf{7 0 . 2} \%$ & $\mathbf{1 0 0 \%}$ \\
\hline
\end{tabular}

$(P=0.014$ Significant $)$

Table 5: Mean dft/DFT at different ages

\begin{tabular}{|c|c|c|}
\hline Age group & Mean dft/DFT & Std. Deviation \\
\hline dft at 6 yrs & 3.17 & 2.942 \\
\hline dft at 10 yrs & 2 & 2.615 \\
\hline dft at 12 yrs & 0.79 & 1.494 \\
\hline DFT at 6 yrs & 0.39 & 0.933 \\
\hline DFT at 10 yrs & 0.66 & 1.168 \\
\hline DFT at 12 yrs & 1.16 & 1.665 \\
\hline
\end{tabular}

Table 6: Dental caries prevalence - BMI category wise

\begin{tabular}{|c|c|c|c|}
\hline \multirow{2}{*}{ BMI category } & \multicolumn{2}{|c|}{$\begin{array}{c}\text { Dental caries } \\
\text { prevalence }\end{array}$} & \multirow{2}{*}{ Total } \\
\cline { 2 - 3 } & $\begin{array}{c}\text { No decay } \\
\text { present }\end{array}$ & $\begin{array}{c}\text { Decay } \\
\text { present }\end{array}$ & \\
\hline Underweight & 33 & 72 & 105 \\
\hline & $31.4 \%$ & $68.6 \%$ & $100 \%$ \\
\hline Normal & 41 & 102 & 143 \\
\hline & $28.7 \%$ & $71.3 \%$ & $100 \%$ \\
\hline Total & $\mathbf{7 4}$ & $\mathbf{1 7 4}$ & $\mathbf{2 4 8}$ \\
\hline & $\mathbf{2 9 . 8} \%$ & $\mathbf{7 0 . 2} \%$ & $\mathbf{1 0 0} \%$ \\
\hline
\end{tabular}

\section{Discussion}

Both malnutrition and dental caries are complex conditions and many biological, genetic, environmental, socioeconomic and behavioral factors are known to be involved ${ }^{7}$. Given the strong evidence supporting the association of dental caries with irregular dietary patterns and quality ${ }^{14}$ and the fact that abnormal dietary intake has been linked to the development of malnutrition at a young age $^{7}$, a link between dental caries and weight is biologically credible.
In our study, $56.5 \%$ of the children had normal BMI, which is less than as reported in a US study $(75 \%)^{15}$. About $42.3 \%$ were underweight, which is much higher than that obtained in the US study $(4 \%)^{15}$. The percentage of underweight children among 6 and 10 years of age were almost equal $(42.3 \%, 46.3 \%)$; whereas, it was lower for children of 12 years of age (38.9\%). The reason for lower prevalence of underweight children among 12 years age could be their partial dependence on mothers for their diet.

In the present study, dental caries was a prevalent disease affecting $70.2 \%$ of the study population. For age group 6 years, the prevalence of dental caries was low in underweight children $(76.7 \%$ versus $87.8 \%)$. The possible explanation could be a delayed tooth eruption among malnourished children which may have resulted in delayed caries development ${ }^{16}$.

Exploration of the link between weight and oral health in children has always been controversial ${ }^{1}$. The result of our study suggested no association existed between dental caries prevalence and body mass index $(p>0.05)$, however the Pearson correlation test showed a negative correlation between body mass index score and number of dental caries in both the deciduous and permanent dentition, which meant children with less BMI score tend to have more approximal caries affected teeth than children with normal BMI. But the association was weak. The reasons for the increased severity of dental caries among children with less BMI score could be low literacy rates, especially among mothers, inaccess to dental care, lack of balance diet, easy access to snacks, junk food-highly cariogenic and low calorie, and above all lack of awareness about proper oral hygiene.

In contrast to our study, a study in elementary school children in Germany found a positive correlation between weight and caries experience in primary and mixed dentitions ${ }^{17}$. Several reports described as inverse relationship between dental caries and weight ${ }^{1,18}$. In a study of children, Chen $\mathrm{W}$ et al reported no association between BMI-for-age and dental caries among 3-yearold Chinese children ${ }^{19}$. In addition, a recent systematic review only identified one study as having a sufficient level of evidence to substantiate a positive correlation between dental caries and weight in a pediatric cohort ${ }^{20}$.

\section{Conclusion}

Physicians and dentists treating young children should consider that malnutrition is a risk marker for childhood caries. For dentists, children presenting with dental caries should be considered at risk for nutritional deficiencies that may affect long-term health and wellbeing. Hence, BMI calculation should be included in the standard dental evaluation of any paediatric patient, as 
it can provide a screen for potential dental complications of the growing child. The goal for both physicians and dentists should be the prevention, timely diagnosis, and treatment of the children suffering from dental caries and malnutrition.

\section{Limitations}

Since convenience sampling was done, sampling bias could have occurred as no attempt was made to randomly select patients for the study. Although we did not perform a formal socioeconomic assessment of our sample, the well-characterized geographic localization of our subjects and known characteristics of the area, in the view of authors, provided homogeneity to the group.

Acknowledgements: None

Funding: Nil

Conflict of Interest: Nil

Permission from IRB: Yes

\section{References}

1. Pinto A, Kim S, Wadenya $\mathrm{R}$, Rosenberg $\mathrm{H}$. Is there an association between weight and dental caries among pediatric patients in an urban dental school? J Dent Educ 2007;71(11):1435-440.

2. The World Bank [Internet]. Washington DC: The World Bank; 2010 [cited 2010 Oct 19]. Available from: http://web.worldbank.org/WBSITE/ EXTERNAL/COUNTRIES/SOUTHASIA.

3. Finlayson TL, Siefert K, Ismail AI, Sohn W. Psychosocial factors and early childhood caries among low-income African-American children in Detroit. Community Dent Oral Epidemiol 2007;35(6):439-48.

4. Svedberg P. Child Malnutrition in India and China. 2020 Focus Brief on the World's Poor and Hungry People. 2007 Washington, DC: IFPRI.

5. Delgado-Angulo EK, Hobdell MH, Bernabé E. Poverty, social exclusion and dental caries of 12-year-old children: a cross sectional study in Lima, Peru. BMC Oral Health 2009, 9:16

6. Fernandez ID, Himes JH, de Onis M. Prevalence of nutritional wasting in populations: building explanatory models using secondary data. Bull World Health Org 2002; 80 (4):282-91.

7. Psoter WJ, Reid BC, Katz RV. Malnutrition and dental caries: A review of the literature. Caries Res 2005; 39 (6):441-47.
8. Van de Poel E, Hosseinpoor AR, Speybroeck N, Van Ourti T, Vega J. Socioeconomic inequality in malnutrition in developing countries. Bull World Health Org 2008;86(4):282-91.

9. Alvarez JO. Nutrition, tooth development, and dental caries. Am J Clin Nutr 1995;61 (suppl): 410S-6S.

10. Gerdin EW, Angbratt M, Aronsson K, Eriksson E, Johansson I. Dental caries and body mass index by socio-economic status in Swedish children. Community Dent Oral Epidemiol 2008; 36(5):45965.

11. Hallett KB, O'Rourke PK. Caries experience in preschool children referred for specialist dental care in hospital. Aust Dent J 2006;51(2):124-9.

12. Livny A, Assali R, Sgan-Cohen HD. Early Childhood Caries among a Bedouin community residing in the eastern outskirts of Jerusalem. BMC Pub Health 2007;7:167.

13. World Health Organization. WHO-Oral Health Survey, Basic methods. $4^{\text {th }}$ ed. New Delhi: AITBS Publishers and distributers; 1999.

14. Dye BA, Shenkin JD, Ogden CL, Marshall TA, Levy SM, Kanellis MJ. The relationship between healthful eating practices and dental caries in children aged 2-5 years in the United States, 1988-1994. J Am Dent Assoc 2004;135:55-66.

15. Clarke M, Locker D, Berall G, Pencharz P, Kenny DJ. Malnourishment in children with severe early childhood caries. Pediatr Dent 2006;28:254-59.

16. Alvarez JO, Caceda J, Woolley TW. A longitudinal study of dental caries in the primary teeth of children who suffer from infant malnutrition. J Dent Res 1993;72:1573-576.

17. Willerhausen B, Blettner M, Kasaj A, Hohenfellner K. Association between body mass index and dental health in 1,290 children of elementary schools in a German city. Clin Oral Investig 2007;11(3):195-200.

18. Sheiham A. Dental caries affects body weight, growth, and quality of life in pre-school children. $\mathrm{Br}$ Dent J 2006;201:625-26.

19. Chen W, Chen P, Chen SC, Shih WT, Hu HC. Lack of association between obesity and dental caries in three-year-old children. Chung-Hua Min Kuo Hsiao Erh Ko I Hseuh Hui Tsa Chih 1998; 39:109-111.

20. Kantovitz KR, Pascon FM, Rontani RM, Gaviao MB. Obesity and dental caries: a systematic review. Oral Health Prev Dent 2006;4:137-44. 